\title{
Association of eating habits and cooking methods with breast tumors among childbearing aged urban women in Indonesia: A cross-sectional study
}

Imaviana Cahyani

Department of Nutrition and Public Health, Esa Unggul University, Jakarta

Adi Kurniawan ( $\sim$ 8lukas@ntunhs.edu.tw )

Research Center for Healthcare Industry Innovation, National Taipei University of Nursing and Health

Sciences

Khairizka Palupi

Department of Nutrition and Public Health, Esa Unggul University, Jakarta

Amadou Jallow

Department of Health Technology, National Taipei University of Nursing and Health Sciences

Rathi Paramastri

School of Nutrition and Health Sciences, College of Nutrition, Taipei Medical University

Mertien Sa'pang

Department of Nutrition and Public Health, Esa Unggul University, Jakarta

\section{Research Article}

Keywords: eating habits, cooking methods, breast tumor, urban women

Posted Date: November 25th, 2020

DOl: https://doi.org/10.21203/rs.3.rs-107967/v1

License: (c) (i) This work is licensed under a Creative Commons Attribution 4.0 International License.

Read Full License 


\section{Abstract}

Background: This study aimed to determine the associations of eating habits and cooking methods with a breast tumor in childbearing aged Indonesian urban women.

Methods: This was a cross-sectional study using a research of non-communicable disease 2016 database from the ministry of health of Indonesia. In total 28558 women, aged 25 - 49 years old were retrieved from the database. Eating habits and cooking methods were measured using a validated food frequency questionnaire. A forward logistic regression analysis was used to examine the association of eating habits and cooking methods with the risk of breast tumors.

Results: Higher education level was positively associated with the incidence of breast tumor $(\mathrm{OR}=1.10$, $95 \% \mathrm{Cl}: 1.01-1.20, p=0.026)$. Seafood ( $\mathrm{OR}=0.88,95 \% \mathrm{Cl}: 0.80-0.96, p=0.006)$ and fast foods $(\mathrm{OR}=1.10$, $95 \% \mathrm{Cl}: 1.00-1.20, p=0.049)$ were significantly associated with the incidence of breast tumor among urban women. Roasted/smoked cooking method was positively associated with risk of breast tumor (OR $=1.27,95 \% \mathrm{Cl}: 1.01-1.61, p=0.043)$.

Conclusion: Our study is the first community-based study in Indonesia investigating the association of eating habits and cooking methods with the incidence of breast tumors among childbearing aged urban women. High intake of seafood was associated with a lower risk of breast tumors while fast foods and roasted/smoked cooking method belief to have a detrimental effect on a breast tumor. Prospective studies are needed to confirm the present study findings.

\section{Introduction}

Worldwide, breast cancer is the single most commonly detected cancer among women and has now become a global health burden [1, 2]. In Indonesia, the incidence of breast cancer continues to increase every year and represents the leading cause of cancer mortality among women [2]. The incident rate of breast cancer may differ by geographical location. Certain environmental and lifestyle factors including diet play a significant role to enhance breast cancer [3]. Literature has shown that diet alone, can accounts for approximately $35 \%$ of all cancer cases. Therefore, it is essential to recognize dietary habits including cooking methods for breast cancer risk [4].

For the past years, a large number of studies have evaluated the association of particular foods with their composition including eating habits with the advancement of breast cancer $[5,6]$. According to the report released by World Cancer Research Fund and the American Institute for Cancer Research (WCRF/AICR) prospected an increase in breast cancer risk among women eating higher-fat diets compared with those eating lower-fat diets [7]. Eating and cooking habits extremely vary among countries or regions. Soy food, which is mainly consumed in Asia has been found to have a low risk for breast cancer among women [8], likewise, total dairy food consumption including milk also appears to be riskless [9]. In contrast, another prospective cohort study conducted in South Korea revealed that consuming high-cholesterol foods, 
grilled meat, and inconsistent eating habits seems to be associated with an elevated risk of breast cancer among adult women [10].

However, most previously published studies on the association of diet and breast cancer were focus on single food items or nutrients. Investigating overall eating habits together with cooking methods might be more significant in determining breast tumor etiology rather than evaluating diets separately as a result of the complexity and combinations of food or nutrients among individuals $[11,12]$. Following healthy eating habits such as fruits, vegetables, fish, olive oil and whole grains is likely to be advantageous to reduce breast cancer among middle-aged women [13]. A study has reported that moderate consumption of pan-fried/bread-coated fried white meat and well-done or stewed red meat have a minimal risk for breast cancer. Moreover, the total intake of processed/cured meat was considered for having a strong association with triple-negative tumors [14]. Preventive dietary measures to deteriorate breast cancer risk could also include the use of olive/liquid oils for cooking and quitting the use of mayonnaise as salad dressing [15]. Since limited studies using a large sample size particularly among Indonesian urban women investigating these issues, therefore in this study, we aimed to determine the associations of eating habits and cooking methods with a breast tumor on childbearing age in Indonesian women.

\section{Methods}

\section{Study population}

This cross-sectional study was used a database from a community survey of research of noncommunicable disease in 2016. This survey was conducted by the Department of research and development Ministry of Health of Republic Indonesia. The major aim of this survey was to obtain the prevalence rate of women aged 25-64 years old with positive breast tumors in urban areas in Indonesia. The survey was conducted on August - September 2016 in selected 76 districts/cities from 34 provinces. Data was collected through interviews and the interviews were conducted at the participant's house by trained enumerators. The enumerators would ask a series of general and personal questions including education status and occupation. They also performed anthropometric and blood pressure measurements. In total, 39188 women were recruited. After excluded those who were $\geq 50$ years old $(n=10258)$ and not having breast tumor examination $(n=372)$, a total of 28558 women were used for the analysis. This study was approved by Esa Unggul University's ethical review board (0180-20.175/DPKEKEP FINAL-EA/UEU/VII/2020).

\section{Assessment of breast tumors}

In this study, the examination of breast tumors used the clinical breast examination method. Meanwhile, a pathology anatomy test was used to confirm breast tumors. A certified medical doctor or midwife carried out the clinical breast examination (inspection and palpation) at the primary healthcare clinics. They assessed breast position (asymmetric or not), the skin of the breast (normal, reddish, swollen, wet wounds or pulling), and the areola of the breast (normal, retracted, wet wounds or abnormal fluid 
appears). Moreover, the palpation examination was carried out to check the lump (number, size, quadrant location, consistency, mobility, and tenderness) and the presence of enlarged lymph nodes at the armpits.

\section{Assessment of eating habits, cooking methods, and other covariates}

A validated food frequency questionnaire (FFQ) was used to assess participants eating habits and cooking methods in the last month. In the FFQ, 106 food items (Additional file 1) were categorized into twelve food groups (meats, eggs, innards organs, processed meats, seafood, milk and dairy products, fast foods, beans or legumes, light-colored vegetables, dark leafy vegetables, fruits, and oils). Meanwhile, seven types of cooking methods, namely roasted/smoked, fried, grilled, boiled, pan-fried/sautéing, steamed, and raw/fresh were also retrieved from the FFQ. Each food item and cooking method had seven response scores (1 to 7) ranged from never, $1 x /$ month, 2-3x/month, 1-2x/week, 3-4x/week, 5-6x/week, and daily. Meats and dark-leafy vegetables consist of seven food items. Processed meats, seafood, and fast foods consist of four food items. Milk and dairy products and beans or legumes consist of nine food items. While eggs, innards organs, light-colored vegetables, fruits, and oils consist of 3, 5, 18, 30, and 6 food items respectively. The minimum and maximum consumption scores for meats, eggs, innards organs, processed meats, seafood, milk and dairy products, fast foods, beans or legumes, light-colored vegetables, dark leafy vegetables, fruits, and oils are 7-49, 3-21, 5-35, 4-28, 4-28, 9-63, 4-28, 9-63, 18-126, $7-49,30-210,6-42$, respectively. Eating habits for each food group were categorized as low (below the median/2-quintile) and high (above the median/2-quintile). Moreover, the cooking methods were categorized as a 'regular' method if they used roasted/smoked, fried, boiled, pan-fried/sautéing, steamed, and raw/fresh cooking methods $\geq 3-4 x /$ week, and grilled cooking method $\geq 2-3 x /$ month, and 'infrequent' if otherwise [10]. Other covariates such as education status were dichotomized as low (below high school) and high (above high school). While working status was categorized as no (not working or still studying) and yes (engaged in professional working).

\section{Data analysis}

Statistical analysis was performed using STATA version 13 (STATA Corp LLC, Texas, USA). A chi-squared test was used to compare the categorical variables among the characteristics of women with breast tumors incidence. A general linear model was used to compare the eating habits score of each food group according to breast tumors incidence. Meanwhile, an adjusted (age, education, and working status) and forward selection of logistic regression was performed to determine the most dominant variables associated with breast tumors among urban women. We used forward logistic regression tests with a predictive model by selecting each independent variable. First, all independent variables that produced pvalue $<0.25$ were selected for further analysis. Second, variables that have met the previous selection criteria will be adjusted one by one (variables with $p$-value $>0.05$ will be removed gradually) until there were only variables with $p<0.05$.

\section{Results}


From a total of 28558 women, $8.3 \%(n=2376)$ of those had a breast tumor. Characteristics of urban women across breast tumor status are shown in Table 1. Positive breast tumor women had higher education levels $(53.9 \%)$, higher consumption score of meats (11.7 \pm 3.4 vs. $11.5 \pm 3.2 ; p=0.006)$, milk and dairy products $(11.3 \pm 3.3$ vs. $11.1 \pm 3.1 ; p=0.015)$, and fast food $(4.8 \pm 1.7$ vs. $4.7 \pm 1.6 ; p=0.010)$ but lower intake of seafood (10.0 \pm 3.8 vs. $10.2 \pm 3.7 ; p=0.011)$. Additionally, positive breast tumor women used fried cooking method regularly $(90.3 \%, p=0.045)$.

Logistic regression analysis revealed that seafood and fast food were significantly associated with the incidence of breast tumor (Table 2). Adjusted and forward logistic regression showed that seafood negatively associated with breast tumor $(\mathrm{OR}=0.91,95 \% \mathrm{Cl}: 0.84-0.99, p=0.028$ and $\mathrm{OR}=0.88,95 \% \mathrm{Cl}$ : $0.85-1.04, p=0.006$ respectively). In contrast, fast foods were associated with increased $10 \%$ risk of breast cancer (95\% Cl: $1.00-1.20, p=0.049)$. Furthermore, only roasted/smoked cooking method was positively associated with the incidence of breast tumor ( $\mathrm{OR}=1.27,95 \% \mathrm{Cl}$ : $1.01-1.61, p=0.043)$ (Table $3)$.

\section{Discussion}

In this study, our evaluation showed that the incidence of breast tumors in Indonesia was significantly associated with higher education levels and fast foods as well as roasted/smoked cooking methods among childbearing-aged urban women. Whereas, total seafood consumption was substantially associated with a low risk of breast tumors incidence. The evidence relating to individual education level to risk for breast cancer is still unclear. Nonetheless, education differences in cancer prevalence have long been observed [16]. However, it is not well known, if such a relationship will continue to exist in Indonesia following adjustment for individual risk factors of breast tumors. The findings of this present study are similar to previous publications of elevated risk of breast tumors among women with higher education levels $[17,18]$. A prospective cohort study conducted in the United State has shown that women with the least education level had a lower risk of invasive breast cancers [16]. In another study, the relationship between education level and cancer risk becomes completely insignificant after multivariate adjustment for unhealthy lifestyles [19]. Perhaps, such analysis might give a plausible description about the connection between education and cancer for public health concern. Inconsistent results have also been observed in several studies conducted to investigate the role of education level in breast tumors survival. Among the studies, one reported no relationship found between education and breast tumors [20], while others revealed a high survival rate among women with lower [21] or higher [22] education level.

Eating habits have been identified to involve both in the development and prevention of breast tumors [23] but the evidence is yet to be cleared [24]. Since breast tumors is a hormone-related malignancy, the diet may enhance its consequences through the hormonal level, anti-oxidation as well as growth factors $[25,26]$. From the literature review, we noticed an increased risk of breast tumor-associated with high consumption of fast foods, which similarly concurred with our study [27]. Fast foods are typically meatsweet diets with a large quantity of sugar and fat, prepared as baked goods, burgers, and deep-fried foods like chips, French fries, and chicken pieces [7]. Furthermore, fast foods have been linked to a diet 
prepared with limited essential nutrients and frequent intake of it may lead to overconsumption of energy [28]. High energy consumption may trigger the release of essential hormonal factors such as estrogen, insulin-like growth factor (IGF)-1, and sex hormone-binding globulin, which all play a significant role in the inhibition of proliferation of cancer cells [29]. A group of researchers from Poland has reported that consuming fast food daily is threefold likely to increase the risk of breast tumors. In their study, they further discovered that refined meat including burgers, sausage, and pizza containing sodium nitrate, is transformed into nitrosamine, which is considered carcinogen [30].

Cooking methods vary among regions or countries; therefore, differences in the incidence rate of breast tumors may occur. The type of cooking methods applied for preparing diet may also have an impact on cancer cell growth. In the recent study, our findings indicated that prepared meals by roasting or smoking are associated with an elevated risk of breast tumors. The roasted or smoked cooking method involved the use of high temperatures to prepare food. During our literature review, no study specifically reported that consuming high-temperature cooked food, for example eating grilled/barbecued and smoked meat, is associated with primary prevention of breast tumors, it is however been reported that women to reduce consuming high-temperature cooked meat due to the formation of carcinogenic compounds [31]. A study conducted among US females showed that grilled/barbecued and smoked meat consumption is the main origin of polycyclic aromatic hydrocarbons (PAHs) [32] and has been regarded to increase the proportion of breast tumors $[33,34]$. PAHs together with another carcinogenic mutagen such as heterocyclic amines (HCAs) are found highly in meat cooked at high temperatures [35]. HCAs are formed when muscle meat which consists of amino acids and creatinine reacts at high temperatures [36]. Meanwhile, PAHs are formed at the surface of the meat when it cooked directly on an open flame, resulting in pyrolysis of the fat. Imperfectly combusted meat also leads to carbon and hydrogen from fat react with hot coals and produce smoke [35].

Among the seafood, fish is the most common for consumption globally, including Indonesia. Increasing evidence has emerged showing an increased risk of breast tumors linked with the intake of seafood (like fresh-water fish and marine fish), which is not in support of other literature conducted distinctively [3739]. Our results are, however, similar to other publications, in which breast cancer risk is reduced with high seafood consumption [40]. Seafood such as fish (oily fish or fish oils) is regarded as the major source of n-3 polyunsaturated fatty acids (n-3 PUFA), which can effectively deteriorate the risk of breast tumors among women $[41,42]$. In addition, fish oil or a diet rich in eicosapentaenoic acid (EPA) and docosahexaenoic acid (DHA) may also inhibit metastases development and further suppress tumor progression [43-45]. However, the epidemiologic evidence showing the relationship between seafood and breast tumors risk is limited to our understanding.

Our study has certain strengths: it is the first study to examine the association of eating habits and cooking methods among childbearing Indonesian urban women. Second, the sample size was selected from 34 provinces in Indonesia, thus it may represent all areas of the Indonesian archipelago. However, several limitations should also be mentioned. First, the cross-sectional study design limits us to identify the causality of the results. Second, potential misclassification bias of self-reported FFQ may occur and 
the questionnaire included only frequency information, not portion size. Therefore, the intake amount for each participant could not be calculated. Finally, the adjustment for confounding variables was modest in our study. Additional residual confounding variables such as energy and protein intake, genetic or family history, and nutritional status may affect the present findings.

\section{Conclusions}

In summary, higher education levels, consumption of fast foods, and roasted/smoked cooking methods were identified as major risk factors associated with the incidence of breast tumors among childbearing aged urban women living in Indonesia. In contrast, only seafood was discovered having reduced risk for breast tumors. The current study appears to provide the possible high- and low-risk factors associated with breast tumors incidence in Indonesia. Therefore, it is substantial to establish awareness and disseminate information about good eating habits and cooking methods to minimize the risks of breast tumors. The findings of this study suggest that changes in eating habits and cooking methods might impact how breast tumors generate. However, the relationship between eating habits and cooking methods in breast tumors is complicated, more studies might be required for clear evidence.

\section{Abbreviations}

WCRF/AICR, World Cancer Research Fund and the American Institute for Cancer Research; FFQ, Food Frequency Questionnaire; IGF-1, Insulin-like Growth Factor 1; PAHs, Polycyclic Aromatic Hydrocarbons; HCAs, Heterocyclic Amines; n-3 PUFA, n-3 Polyunsaturated Fatty Acids; EPA, Eicosapentaenoic Acid; DHA, Docosahexaenoic Acid.

\section{Declarations}

\section{Author's contributions:}

ALK, IC, KCP and MS conceived and designed the study; IC, KCP, and MS managed and retrieved the data; ALK and IC analyzed the data and performed the statistical analysis; ALK, IC, AWJ, and RP wrote the manuscript. All authors have read and approved the final version of the manuscript.

\section{Funding:}

This research received no external funding.

\section{Conflict of interest:}

The authors declare no conflict of interest.

\section{Ethics approval:}


The Esa Unggul University's ethical review board (0180-20.175/DPKE-KEP FINAL-EA/UEU/VII/2020) approved the study and all methods were performed in accordance with the relevant guidelines and regulations.

\section{Consent to participate:}

All the participants signed a written informed consent authorized by the Department of research and development Ministry of Health of Republic Indonesia.

\section{Consent for publication:}

The data provided by the department of research and development, Ministry of Health of Republic Indonesia to the researchers did not include any personal information and all participants were adults.

\section{Availability of data and material:}

The data that support the findings of this study are restricted for research use only. The data are not publicly available. Data are available for the authors upon reasonable request and with permission of the department of research and development, Ministry of Health of Republic Indonesia.

\section{Acknowledgments:}

The authors thank the department of research and development, Ministry of Health of Republic Indonesia for collecting and providing their database available for this study.

\section{References}

1. Ghoncheh M, Momenimovahed Z, Salehiniya H. Epidemiology, incidence and mortality of breast cancer in asia. Asian Pac J Cancer Prev. 2016;17:47-52.

2. Solikhah S Matahari R, Utami FP, Handayani L, Marwati TA. Breast cancer stigma among Indonesian women: a case study of breast cancer patients. BMC Womens Health. 2020;20:116.

3. Jevtic M, Velicki R, Popovic M, Cemerlic-Adjic N, Babovic SS, Velicki L. Dietary influence on breast cancer. J BUON. 2010;15:455-61.

4. Guo J, Wei W, Zhan L. Red and processed meat intake and risk of breastcancer: a meta-analysis of prospective studies. Breast Cancer Res Treat. 2015;151:191-8.

5. Michels KB, Mohllajee AP, Roset-Bahmanyar E, Beehler GP, Moysich KB. Diet and breast cancer: a review of the prospective observational studies. Cancer. 2007;109 Suppl 12:2712-49.

6. Thomson CA. Diet and breast cancer: understanding risks and benefits. Nutr Clin Pract. 2012;27:636-50.

7. World Cancer Research Fund, and American Institute for Cancer Research. Food, nutrition, physical activity, and the prevention of cancer: a global perspective. Amer Inst for Cancer Research, Washington. 2007 
8. Wei Y, Lv J, Guo Y, Bian Z, Gao M, Du H, et al. Soy intake and breast cancer risk: a prospective study of 300,000 Chinese women and a dose-response meta-analysis. Eur J Epidemiol. 2020;35:567-78.

9. Dong JY, Zhang L, He K, Qin LQ. Dairy consumption and risk of breast cancer: a meta-analysis of prospective cohort studies. Breast Cancer Res Treat. 2011;127:23-31.

10. Kim JH, Lee J, Jung SY, Kim J. Dietary factors and female breast cancer risk: a prospective cohort study. Nutrients. 2017;9:1331

11. Mannisto S, Dixon LB, Balder HF, Virtanen MJ, Krogh V, Khani BR, et al. Dietary patterns and breast cancer risk: results from three cohort studies in the DIETSCAN project. Cancer Causes Control. 2005;16:725-33.

12. Jacques PF, Tucker KL. Are dietary patterns useful for understanding the role of diet in chronic disease?. Am J Clin Nutr. 2001;73:1-2.

13. Mourouti N, Papavagelis C, Plytzanopoulou P, Kontogianni M, Vassilakou T, Malamos N, et al. Dietary patterns and breast cancer: a case-control study in women. Eur J Nutr. 2015; 54:609-17.

14. Boldo E, Castelló A, Aragonés N, Amiano P, Pérez-Gómez B, Castaño-Vinyals G, et al Meat intake, methods and degrees of cooking and breast cancer risk in the MCC-Spain study. Maturitas. 2018;110:62-70

15. Mobarakeh ZS, Mirzaei K, Hatmi N, Ebrahimi M, Dabiran S, Sotoudeh G. Dietary habits contributing to breast cancer risk among Iranian women. Asian Pac J Cancer Prev. 2014; 15:9543-47.

16. Mouw T, Koster A, Wright ME, Blank MM, Moore SC, Hollenbeck A, et al. Education and risk of cancer in a large cohort of men and women in the United States. PLoS One. 2008; 3:e3639.

17. Hussain SK, Altieri A, Sundquist J, Hemminki K. Influence of education level on breast cancer risk and survival in Sweden between 1990 and 2004. Int J Cancer. 2008;122:165-9.

18. Braaten T, Weiderpass E, Kumle M, Adami HO, Lund E. Education and risk of breast cancer in the Norwegian-Swedish women's lifestyle and health cohort study. Int J Cancer. 2004;110:579-83.

19. Braaten $T$, Weiderpass $E$, Kumle $M$, Lund E. Explaining the socioeconomic variation in cancer risk in the Norwegian Women and Cancer Study. Cancer Epidemiol Biomarkers Prev. 2005;14:2591-7.

20. Lund E, Jacobsen BK. Education and breast cancer mortality: experience from a large Norwegian cohort study. Cancer Causes Control. 1991;2:235-8.

21. Heck KE, Wagener DK, Schatzkin A, Devesa SS, Breen N. Socioeconomic status and breast cancer mortality, 1989 through 1993: an analysis of education data from death certificates. Am J Public Health. 1997;87:1218-22.

22. Carter CL, Jones DY, Schatzkin A, Brinton LA. A prospective study of reproductive, familial and socioeconomic risk factors for breast cancer using NHANES I data. Public Health Rep. 1989;104:4550.

23. Rossi RE, Pericleous M, Mandair D, Whyand T, Caplin ME. The role of dietary factors in prevention and progression of breast cancer. Anticancer Res. 2014;34:6861-75. 
24. Adami HO, Hunter DJ, Trichopoulos D, editors. Textbook of cancer epidemiology. Oxford University Press, USA; 2008.

25. Linos E, Willett WC. Diet and breast cancer risk reduction. J Natl Compr Canc Netw. 2007; 5:711-8.

26. Wiseman M. The second World Cancer Research Fund/American Institute for Cancer Research expert report. Food, nutrition, physical activity, and the prevention of cancer: a global perspective. Proc Nutr Soc. 2008;67:253-6.

27. Chandran U, McCann SE, Zirpoli G, Gong Z, Lin Y, Hong CC, et al. Intake of energy-dense foods, fast foods, sugary drinks, and breast cancer risk in African American and European American women. Nutr Cancer. 2014;66:1187-99.

28. Anderson B, Rafferty AP, Lyon-Callo S, Fussman C, Imes G. Fast-food consumption and obesity among Michigan adults. Prev Chronic Dis. 2011;8:A71.

29. Harvie M, Howell A. Energy balance adiposity and breast cancer - energy restriction strategies for breast cancer prevention. Obes Rev. 2006;7:33-47.

30. Plagens-Rotman K, Piskorz-Szymendera M, Chmaj-Wierzychowska K, Pieta B. Breast cancer Analysis of the selected risk factors. Eur J Gynaecol Oncol. 2017;38:425-30.

31. Moorthy B, Chu C, Carlin DJ. Polycyclic aromatic hydrocarbons: from metabolism to lung cancer. Toxicol Sci. 2015;145:5-15.

32. Steck SE, Gaudet MM, Eng SM, Britton JA, Teitelbaum SL, Neugut Al, et al. Cooked meat and risk of breast cancer-lifetime versus recent dietary intake. Epidemiology. 2007; 18:373-82.

33. Parada H, Jr., Steck SE, Bradshaw PT, Engel LS, Conway K, Teitelbaum SL, et al. Grilled, barbecued, and smoked meat intake and survival following breast cancer. J Natl Cancer Inst. 2017;109:djw299.

34. White AJ, Bradshaw PT, Herring AH, Teitelbaum SL, Beyea J, Stellman SD, et al. Exposure to multiple sources of polycyclic aromatic hydrocarbons and breast cancer incidence. Environ Int. 2016;8990:185-92.

35. Abid Z, Cross AJ, Sinha R. Meat, dairy, and cancer. Am J Clin Nutr. 2014, 100 Suppl 1:386S-93S.

36. Jagerstad M, Skog K: Formation of meat mutagens. Adv Exp Med Biol. 1991;289:83-105.

37. Genkinger JM, Makambi KH, Palmer JR, Rosenberg L, Adams-Campbell LL. Consumption of dairy and meat in relation to breast cancer risk in the Black Women's Health Study. Cancer Causes Control. 2013;24:675-84.

38. Kim AE, Lundgreen A, Wolff RK, Fejerman L, John EM, Torres-Mejia G, et al. Red meat, poultry, and fish intake and breast cancer risk among Hispanic and Non-Hispanic white women: The Breast Cancer Health Disparities Study. Cancer Causes Control. 2016; 27:527-43.

39. Kiyabu GY, Inoue M, Saito E, Abe SK, Sawada N, Ishihara J, et al. Fish, $n$ - 3 polyunsaturated fatty acids and $\mathrm{n}-6$ polyunsaturated fatty acids intake and breast cancer risk: The Japan Public Health Center-based prospective study. Int J Cancer. 2015; 137:2915-26.

40. Haraldsdottir A, Steingrimsdottir L, Valdimarsdottir UA, Aspelund T, Tryggvadottir L, Harris TB, et al: Early life residence, fish consumption, and risk of breast cancer. Cancer Epidemiol Biomarkers Prev. 
2017;26:346-54.

41. Brasky TM, Lampe JW, Potter JD, Patterson RE, White E. Specialty supplements and breast cancer risk in the VITamins And Lifestyle (VITAL) Cohort. Cancer Epidemiol Biomarkers Prev. 2010;19:1696708.

42. Zheng JS, Hu XJ, Zhao YM, Yang J, Li D. Intake of fish and marine n-3 polyunsaturated fatty acids and risk of breast cancer: meta-analysis of data from 21 independent prospective cohort studies. Bmj. 2013;346:f3706.

43. Kim J, Lim SY, Shin A, Sung MK, Ro J, Kang HS, et al. Fatty fish and fish omega-3 fatty acid intakes decrease the breast cancer risk: a case-control study. Bmc Cancer. 2009;9:216.

44. Rose DP, Connolly JM. Effects of dietary omega-3 fatty acids on human breast cancer growth and metastases in nude mice. J Natl Cancer Inst. 1993;85:1743-47.

45. Rose DP, Connolly JM, Rayburn J, Coleman M. Influence of diets containing eicosapentaenoic or docosahexaenoic acid on growth and metastasis of breast cancer cells

\section{Tables}

Table 1. Characteristics of study participants according to breast tumor status 


\begin{tabular}{|c|c|c|c|c|}
\hline & \multirow{2}{*}{$\begin{array}{l}\text { All } \\
(n=28558)\end{array}$} & \multicolumn{2}{|l|}{ Breast tumor } & \multirow[t]{2}{*}{$P^{a}$} \\
\hline & & $\begin{array}{l}\text { Negative } \\
(n=26182)\end{array}$ & $\begin{array}{l}\text { Positive } \\
(n=2376)\end{array}$ & \\
\hline Age, years & $38.4 \pm 6.6$ & $38.4 \pm 6.6$ & $38.6 \pm 6.6$ & \\
\hline Education level & & & & 0.028 \\
\hline Low & $13788(48.3)$ & $12692(48.5)$ & $1096(46.1)$ & \\
\hline High & $14770(51.7)$ & $13490(51.5)$ & $1280(53.9)$ & \\
\hline Working status & & & & 0.05 \\
\hline No & $18222(63.8)$ & $16750(64.0)$ & $1472(62.0)$ & \\
\hline Yes & $10336(36.2)$ & $9432(36.0)$ & $904(38.0)$ & \\
\hline Alcohol drinking & & & & 0.368 \\
\hline No & 27695 (97.0) & $25398(97.0)$ & $2297(96.7)$ & \\
\hline Yes & $863(3.0)$ & $784(3.0)$ & $79(3.3)$ & \\
\hline \multicolumn{5}{|l|}{ Food consumption score } \\
\hline Meats & $11.5 \pm 3.3$ & $11.5 \pm 3.2$ & $11.7 \pm 3.4$ & 0.006 \\
\hline Eggs & $7.6 \pm 3.2$ & $7.6 \pm 3.2$ & $7.7 \pm 3.3$ & 0.242 \\
\hline Innards organs & $5.8 \pm 1.5$ & $5.8 \pm 1.5$ & $5.9 \pm 1.6$ & 0.096 \\
\hline Processed meats & $5.8 \pm 2.3$ & $5.8 \pm 2.3$ & $5.9 \pm 2.3$ & 0.473 \\
\hline Seafood & $10.2 \pm 3.7$ & $10.2 \pm 3.7$ & $10.0 \pm 3.8$ & 0.011 \\
\hline Milk and dairy products & $11.1 \pm 3.1$ & $11.1 \pm 3.1$ & $11.3 \pm 3.3$ & 0.015 \\
\hline Beans or legumes & $19.0 \pm 4.9$ & $19.0 \pm 4.9$ & $19.0 \pm 4.9$ & 0.554 \\
\hline Light colored vegetables & $35.5 \pm 12.6$ & $35.5 \pm 12.6$ & $35.7 \pm 12.7$ & 0.609 \\
\hline Dark-leafy vegetables & $15.3 \pm 4.4$ & $15.3 \pm 4.4$ & $15.4 \pm 4.5$ & 0.861 \\
\hline Fruits & $44.6 \pm 12.3$ & $44.6 \pm 12.3$ & $44.5 \pm 12.3$ & 0.877 \\
\hline Oils & $13.4 \pm 2.8$ & $13.4 \pm 2.8$ & $13.5 \pm 3.0$ & 0.500 \\
\hline Fast foods & $4.8 \pm 1.6$ & $4.7 \pm 1.6$ & $4.8 \pm 1.7$ & 0.010 \\
\hline \multicolumn{5}{|l|}{ Cooking method ${ }^{\mathrm{b}}$} \\
\hline Roasted/smoked & & & & 0.035 \\
\hline Infrequent & 27756 (97.2) & 25463 (97.2) & $2293(96.5)$ & \\
\hline
\end{tabular}




\begin{tabular}{|c|c|c|c|c|}
\hline & \multicolumn{2}{|c|}{ Adjusted logistic regression } & \multicolumn{2}{|c|}{ Forward logistic regression } \\
\hline & OR (95\% Cl) & $P$ & OR $(95 \% \mathrm{Cl})$ & $P$ \\
\hline \multicolumn{5}{|c|}{ Meats } \\
\hline Low & 1.00 & & 1.00 & \\
\hline High & $1.02(0.94-1.11)$ & 0.605 & $1.00(0.91-1.10)$ & 0.969 \\
\hline \multicolumn{5}{|l|}{ Eggs } \\
\hline Low & 1.00 & & 1.00 & \\
\hline High & $1.08(0.99-1.18)$ & 0.072 & $1.09(0.99-1.20)$ & 0.069 \\
\hline \multicolumn{5}{|c|}{ Innards organs } \\
\hline Low & 1.00 & & 1.00 & \\
\hline High & $1.04(0.95-1.13)$ & 0.444 & $1.03(0.93-1.14)$ & 0.572 \\
\hline \multicolumn{5}{|c|}{ Processed meats } \\
\hline Low & 1.00 & & 1.00 & \\
\hline High & $0.98(0.90-1.07)$ & 0.705 & $0.94(0.85-1.04)$ & 0.234 \\
\hline \multicolumn{5}{|c|}{ Seafood } \\
\hline Low & 1.00 & & 1.00 & \\
\hline High & $0.91(0.84-0.99)$ & 0.028 & $0.88(0.80-0.96)$ & 0.006 \\
\hline \multicolumn{5}{|c|}{ Milk and dairy products } \\
\hline Low & 1.00 & & 1.00 & \\
\hline High & $1.07(0.99-1.17)$ & 0.105 & $1.06(0.97-1.16)$ & 0.167 \\
\hline \multicolumn{5}{|c|}{ Beans or legumes } \\
\hline Low & 1.00 & & 1.00 & \\
\hline High & $1.02(0.94-1.11)$ & 0.658 & $1.01(0.92-1.11)$ & 0.835 \\
\hline \multicolumn{5}{|c|}{ Light-colored vegetables } \\
\hline Low & 1.00 & & 1.00 & \\
\hline High & $0.99(0.92-1.09)$ & 0.973 & $0.98(0.88-1.10)$ & 0.760 \\
\hline \multicolumn{5}{|c|}{ Dark-leafy vegetables } \\
\hline Low & 1.00 & & 1.00 & \\
\hline High & $1.02(0.93-1.11)$ & 0.693 & $1.02(0.92-1.12)$ & 0.720 \\
\hline
\end{tabular}




\begin{tabular}{|c|c|c|c|c|}
\hline Low & 1.00 & & 1.00 & \\
\hline High & $1.01(0.93-1.10)$ & 0.871 & $0.99(0.89-1.10)$ & 0.911 \\
\hline \multicolumn{5}{|l|}{ Oils } \\
\hline Low & 1.00 & & 1.00 & \\
\hline High & $0.98(0.90-1.07)$ & 0.677 & $0.98(0.90-1.08)$ & 0.732 \\
\hline \multicolumn{5}{|c|}{ Fast foods } \\
\hline Low & 1.00 & & 1.00 & \\
\hline High & $1.11(1.02-1.22)$ & 0.018 & $1.10(1.00-1.20)$ & 0.049 \\
\hline \multicolumn{5}{|c|}{ a adjusted by age, education level, and working status } \\
\hline \multicolumn{5}{|c|}{$\begin{array}{l}\text { Low: < median/2-quintile scores of } 11.0 \text { (meats), } 7.0 \text { (eggs), } 5.0 \text { (innards organs), } 5.0 \text { (processed } \\
\text { meats), } 10.0 \text { (seafood), } 9.0 \text { (milk and dairy products), } 18.0 \text { (beans or legumes), 33.0 (light colored } \\
\text { vegetables), } 15.0 \text { (dark-leafy vegetables), } 41.0 \text { (fruits), } 12.0 \text { (oils), and } 4.0 \text { (fast foods); high if } \\
\text { otherwise. }\end{array}$} \\
\hline
\end{tabular}

Table 3. Logistic regression of cooking methods and incidence of breast tumor 


\begin{tabular}{|c|c|c|c|c|}
\hline & \multicolumn{2}{|c|}{ Adjusted logistic regression a } & \multicolumn{2}{|c|}{ Forward logistic regression } \\
\hline & OR $(95 \% \mathrm{Cl})$ & $P$ & OR (95\% Cl) & $P$ \\
\hline \multicolumn{5}{|c|}{ Roasted/smoked } \\
\hline Infrequent & 1.00 & & 1.00 & \\
\hline Regular & $1.28(1.01-1.61)$ & 0.04 & $1.27(1.01-1.61)$ & 0.043 \\
\hline \multicolumn{5}{|l|}{ Deep-fried } \\
\hline Infrequent & 1.00 & & 1.00 & \\
\hline Regular & $0.86(0.74-0.99)$ & 0.038 & $0.87(0.75-1.01)$ & 0.066 \\
\hline \multicolumn{5}{|l|}{ Grilled } \\
\hline Infrequent & 1.00 & & 1.00 & \\
\hline Regular & $1.12(0.99-1.28)$ & 0.079 & $1.10(0.96-1.26)$ & 0.168 \\
\hline \multicolumn{5}{|l|}{ Boiled } \\
\hline Infrequent & 1.00 & & 1.00 & \\
\hline Regular & $0.99(0.91-1.08)$ & 0.894 & $0.99(0.91-1.09)$ & 0.911 \\
\hline \multicolumn{5}{|c|}{ Pan-fried/Sautéing } \\
\hline Infrequent & 1.00 & & 1.00 & \\
\hline Regular & $0.98(0.90-1.06)$ & 0.586 & $0.98(0.90-1.07)$ & 0.637 \\
\hline \multicolumn{5}{|l|}{ Steamed } \\
\hline Infrequent & 1.00 & & 1.00 & \\
\hline Regular & $1.16(0.97-1.38)$ & 0.100 & $1.13(0.94-1.35)$ & 0.186 \\
\hline \multicolumn{5}{|l|}{ Raw/fresh } \\
\hline Infrequent & 1.00 & & 1.00 & \\
\hline Regular & $1.01(0.93-1.10)$ & 0.821 & $1.03(0.94-1.12)$ & 0.550 \\
\hline \multicolumn{5}{|c|}{ a adjusted by age, education level, and working status } \\
\hline \multicolumn{5}{|c|}{$\begin{array}{l}\text { "Infrequent" was defined as } \leq 1-2 \text { times/week (roasted/smoked, fried, boiled, pan-fried/sautéing, } \\
\text { steamed, raw/fresh) and } \leq 2-3 \text { times/month (grilled) while "regular" if otherwise. }\end{array}$} \\
\hline
\end{tabular}

\section{Supplementary Files}

This is a list of supplementary files associated with this preprint. Click to download. 
- SupplementaryTable1.docx 